\begin{tabular}{|c|c|}
\hline 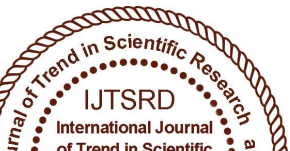 & $\begin{array}{l}\text { International Journal of Trend in Scientific } \\
\text { Research and Development (IJTSRD) }\end{array}$ \\
\hline 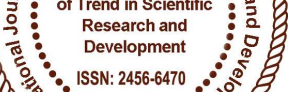 & International Open Access Journal \\
\hline 000 & ISSN No: 2456 - 6470 | www.ijtsrd.com | Volume - 2 | Issue -5 \\
\hline
\end{tabular}

\title{
Simulation of Power Electronic Converter Circuits Using COM3LAB Learning Software in Teaching: A Case Study
}

\author{
Khin Myo Aye \\ Lecturer, Department of Electronic Engineering, \\ Technological University, Loikaw, Kayah State, Myanmar
}

\begin{abstract}
Power electronics concepts are difficult to explain using conventional teaching tools. Use of COMB3LAB software in teaching provides additional support forvisual representations of power converter circuits operation and waveforms. Models of different power electronics converters are prepared on COMB3LAB software and generate simulation waveforms. This paper is helpful for the faculty of electrical engineering to find the various applications of COM3LAB software in teaching.
\end{abstract}

Keywords: COMB3LAB, power electronics, simulation, teaching.

\section{INTRODUCTION}

The focus of this paper was aimed at providing better learning support for enhanced concept and procedural learning in power electronics using software based teaching approach. Power electronics converters are used to change the characteristics (voltage and current magnitude and/or frequency) of electrical power to suit a particular application. The power conversion systems can be classified according to the type of the input and output power such as rectifier (AC to DC), inverter (DC to $\mathrm{AC}$ ), chopper (DC to $\mathrm{DC}$ ), cycloconverter (AC to AC). Software based teaching approach provides a platform the student to work efficiently with practical feedback when designing real world system. Simulation process is very useful due to advanced development in technology. In this paper, power electronics converters (rectifiers) are implemented and simulated by using COMB3LAB learning software. It is suitable for independent learning and experimenting as well as for complete teaching units and project work. The three components: master unit, experiment board and

interactive teaching software turn to one laboratory. Here the simulation of converters is presented using COMB3LAB software.

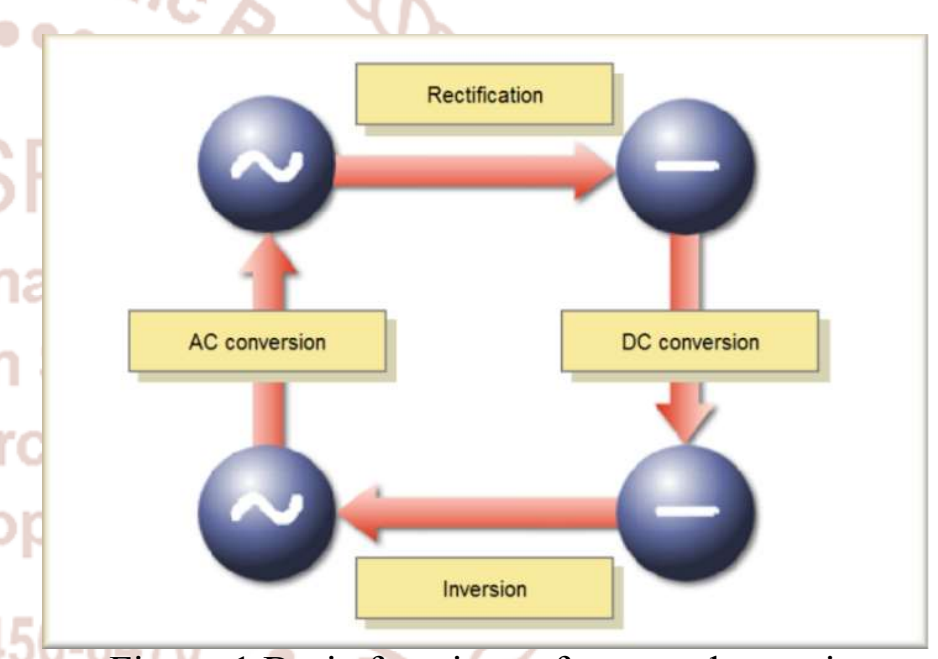

Figure-1 Basic functions of power electronic converters

\section{Single Phase Full Controlled Half-Wave Rectifier}

Unlike diode rectifier, phase controlled rectifier has an advantage of controlling the output voltage. The diode rectifiers are called uncontrolled rectifiers. When these diodes are replaced with thyristors, then it becomes phase controlled rectifier. The output voltage can be controlled by varying the firing angle of the thyristors. The SCR blocks the flows of current during the negative half of a voltage cycle. If no firing pulse is applied during the positive half-cycle, the device will then block the flow of current. In the controlled half-wave circuit, the SCR is ready to conduct during the positive half-cycle of the ac input. It starts conducting at $\omega \mathrm{t}=\alpha$, but beyond $\omega \mathrm{t}=\pi$, the SCR will become reverse biased as the input cycle goes 
negative. The dc output voltage is controlled by varying the triggering angle $\alpha$ at which the SCR (T) starts conducting. This type of rectifier uses a single Thyristor device to provide output control only in one half cycle of input AC supply, and it offers low DC output.

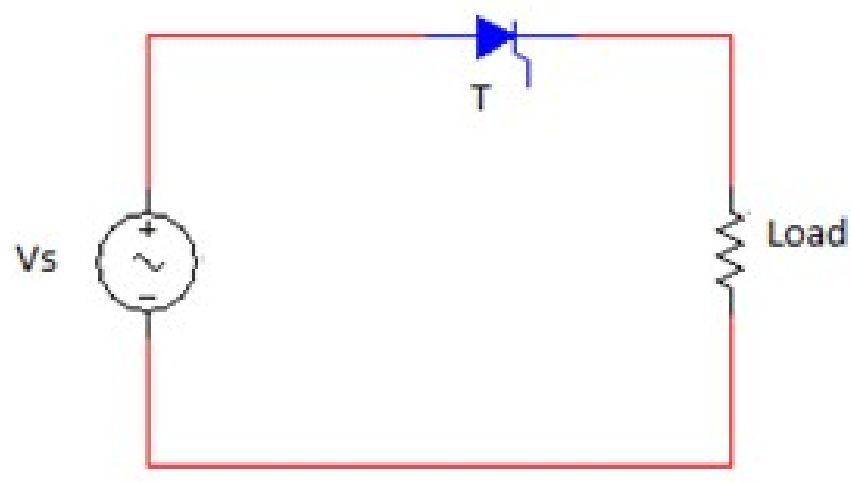

Figure-2.1Single phase full controlled half-wave rectifier circuit

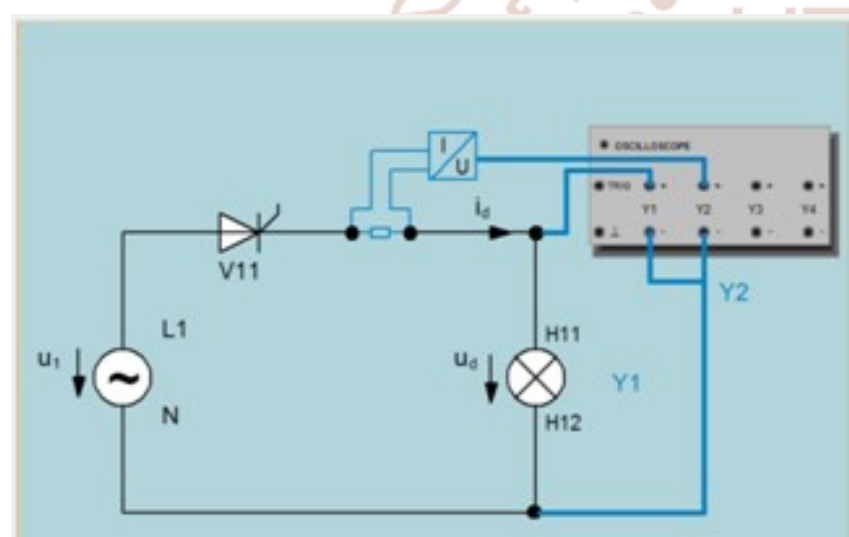

Figure-2.2Single phase full controlled half-wave rectifier (Simulation model)

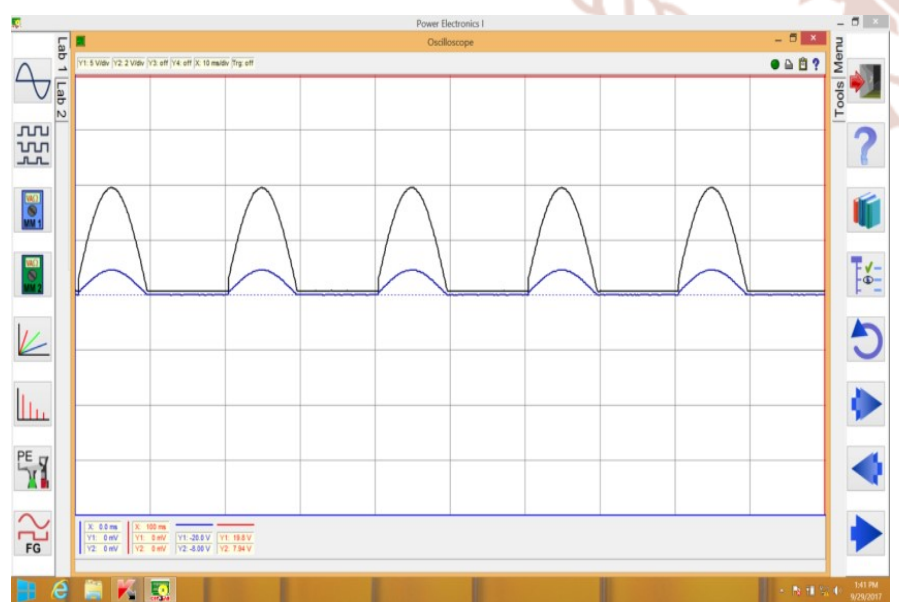

Figure-2.3 Simulated output voltage and current waveforms(Triggering Angle $\alpha=10^{\circ}$ )

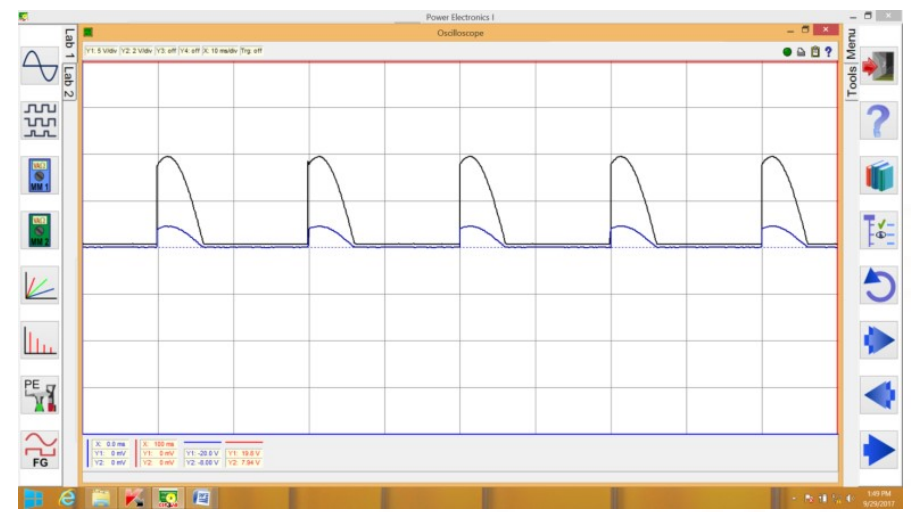

Figure-2.4 Simulated output voltage and current waveforms(Triggering Angle $\alpha=60^{\circ}$ )

\section{Single Phase Uncontrolled full-Wave Bridge Rectifier}

Figure shows the circuit diagram of single-phase uncontrolled full-wave bridge rectifier. It consists of four diodes for converting $\mathrm{AC}$ into $\mathrm{DC}$. The pair $\mathrm{D}_{1}$ $\mathrm{D}_{4}$ and $\mathrm{D}_{2}-\mathrm{D}_{3}$ conducts alternately. In the positive half-cycle of ac input the pair $\mathrm{D}_{1}-\mathrm{D}_{4}$ is $\mathrm{ON}$. In the negative half-cycle, the pair $\mathrm{D}_{1}-\mathrm{D}_{4}$ is OFF as they are reverse biased and then diode $\mathrm{D}_{2}$ and $\mathrm{D}_{3}$ are forward biased and then ON. The currents flowing through the load $\mathrm{i}_{\mathrm{D} 1-\mathrm{D} 4}$ and $\mathrm{i}_{\mathrm{D} 2-\mathrm{D} 3}$ are the same direction. The voltage developed across the load is also unidirectional.

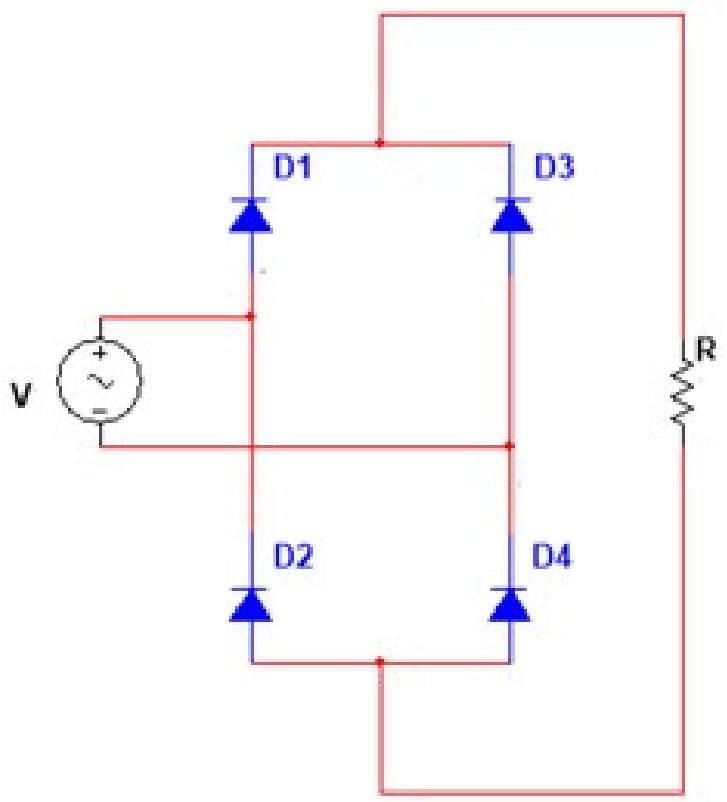

Figure-3.1Single phase uncontrolled full-wave bridgerectifier circuit

The period of the load voltage for the full-wave rectifier is $\pi$, thus, the average output voltage of the full-wave rectifier is twice that of thehalf-wave rectifier. 
International Journal of Trend in Scientific Research and Development (IJTSRD) ISSN: 2456-6470

$$
V_{0}=\frac{2 V_{m}}{\pi}
$$

\section{Single Phase Full-Controlled full-Wave Bridge Rectifier}

The average load current is also twice that of the halfwave rectifier,

$$
I_{0}=\frac{2 V_{m}}{\pi R}
$$

The average diode current of the full-wave rectifier is the same as that of the half-wave circuit because only one pair of diode is forward-biased during one cycle of the source voltage.

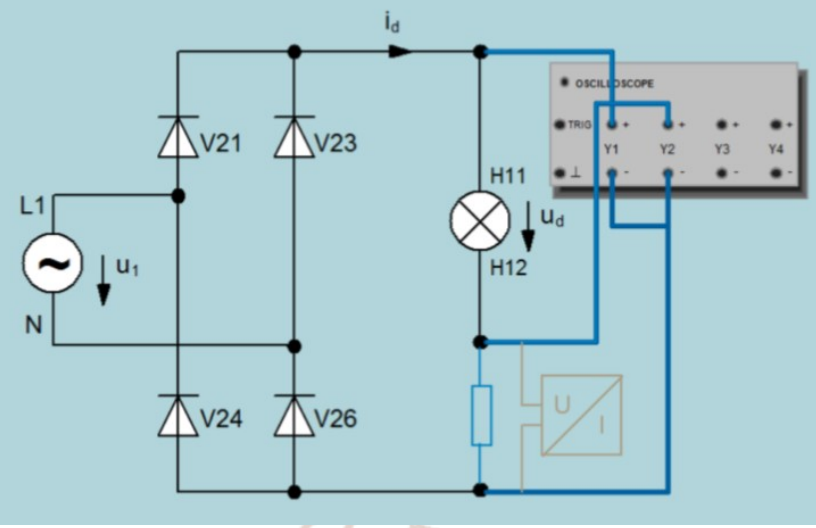

Figure-3.2Single phase uncontrolled full-wave rectifier (Simulation model)

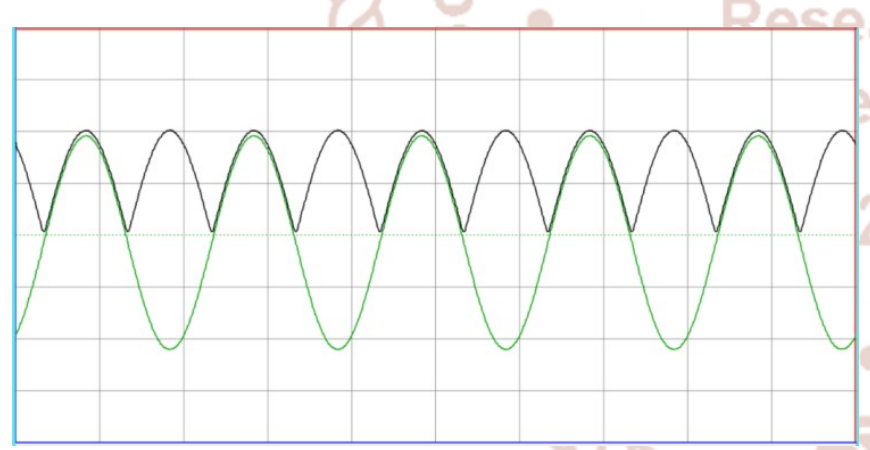

Figure-3.3 Simulated input and output voltage waveforms

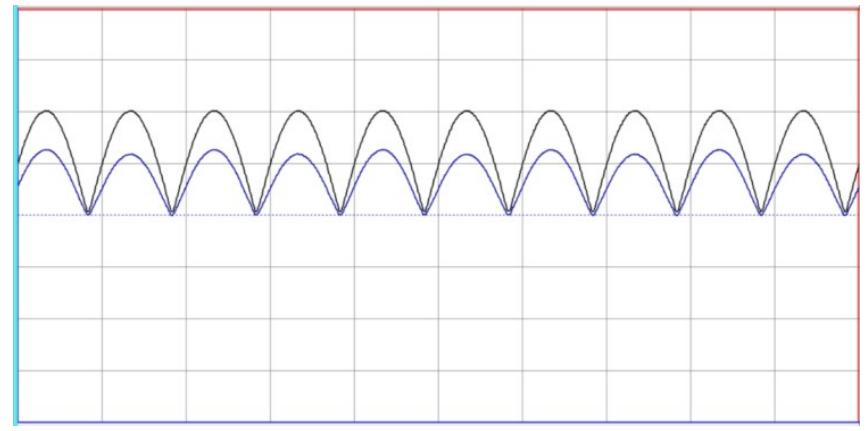

Figure-3.4 Simulated output voltage and current waveforms

Let us assume that the circuit is switched on at $\omega t=0$ and let the firing angle bea. Let the supply voltage $\mathrm{V}_{\mathrm{s}}(\omega \mathrm{t})=\mathrm{Esin}(\omega \mathrm{t})$. When $\omega \mathrm{t}=\alpha$, the SCRs $\mathrm{T}_{1}$ and $\mathrm{T}_{4}$ get triggered and they start conducting since they are forward biased. The two SCRs continue to conduct till $\omega t=\pi$. When $\omega t=\pi$ radians, the supply voltage falls to zero and the current through the SCRs $\mathrm{T}_{1}$ and $\mathrm{T}_{4}$ falls below the holding level and they cease to conduct. When $\pi<\omega t<2 \pi, V_{s}$ is negative. When $V_{s}$ is negative SCR $T_{1}$ and $T_{4}$ are reverse biased and cannot conduct. However, the SCRs $T_{2}$ and $T_{3}$ are forward-biased when $\mathrm{V}_{\mathrm{s}}$ is negative and they get triggered when $\omega \mathrm{t}=$ $\pi+a$ radians and the SCRs $T_{2}$ and $T_{3}$ continue to conduct till $\omega \mathrm{t}=2 \pi$ radians. During the periods defined by $0<\omega t<\alpha$ and $\pi<\omega t<\pi+\alpha$, no SCRs is in conduction and the output voltage is zero. The conduction of the load is discontinuous.

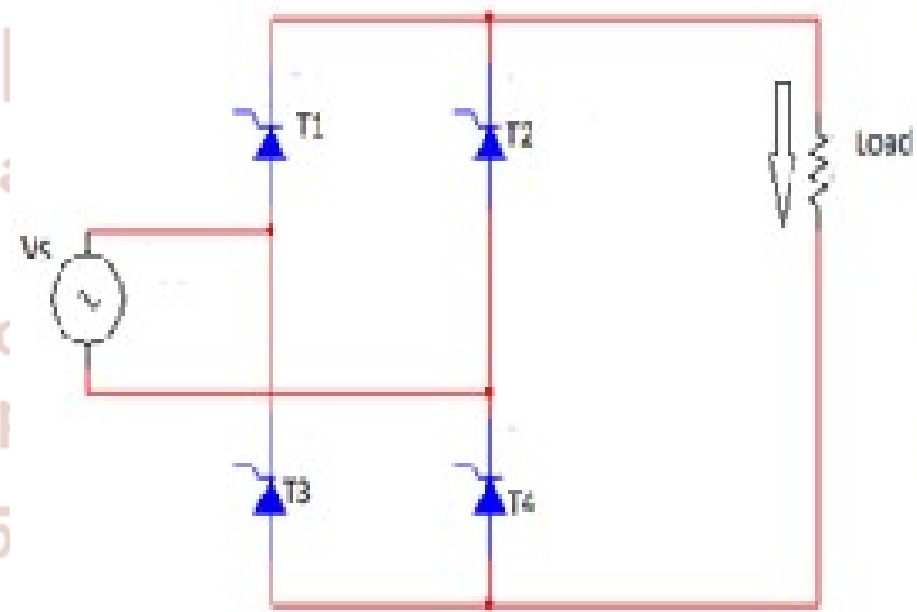

Figure-4.1Single phase full controlled full-wave rectifier circuit

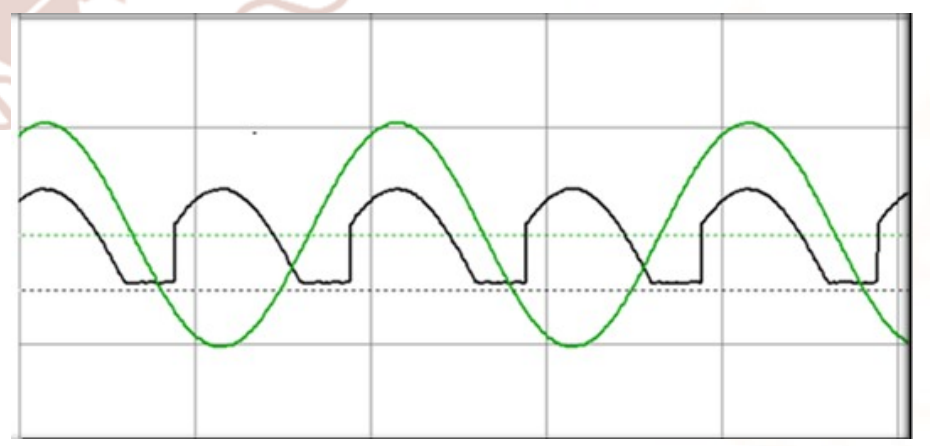

Figure-4.2 Simulated input and output voltage

waveforms 


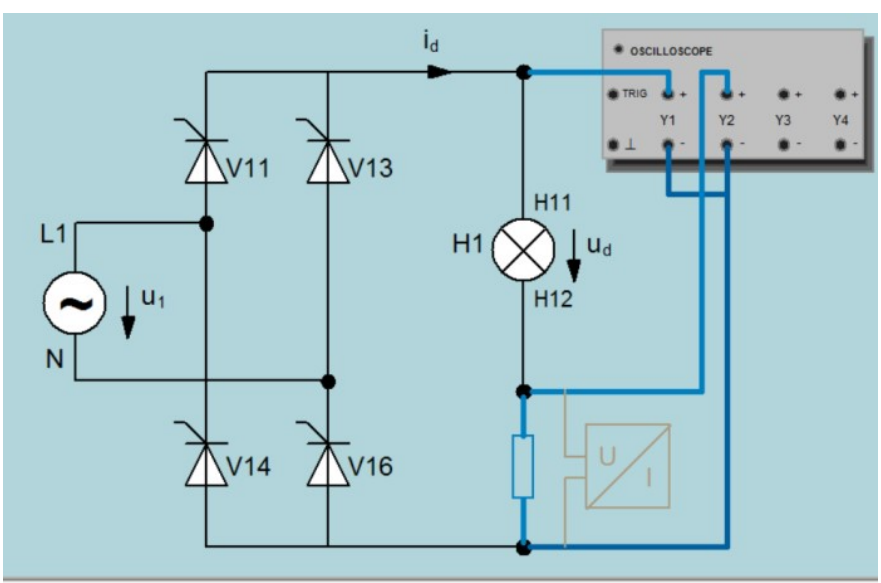

Figure-4.3Single phase full-controlled full-wave rectifier (Simulation model)

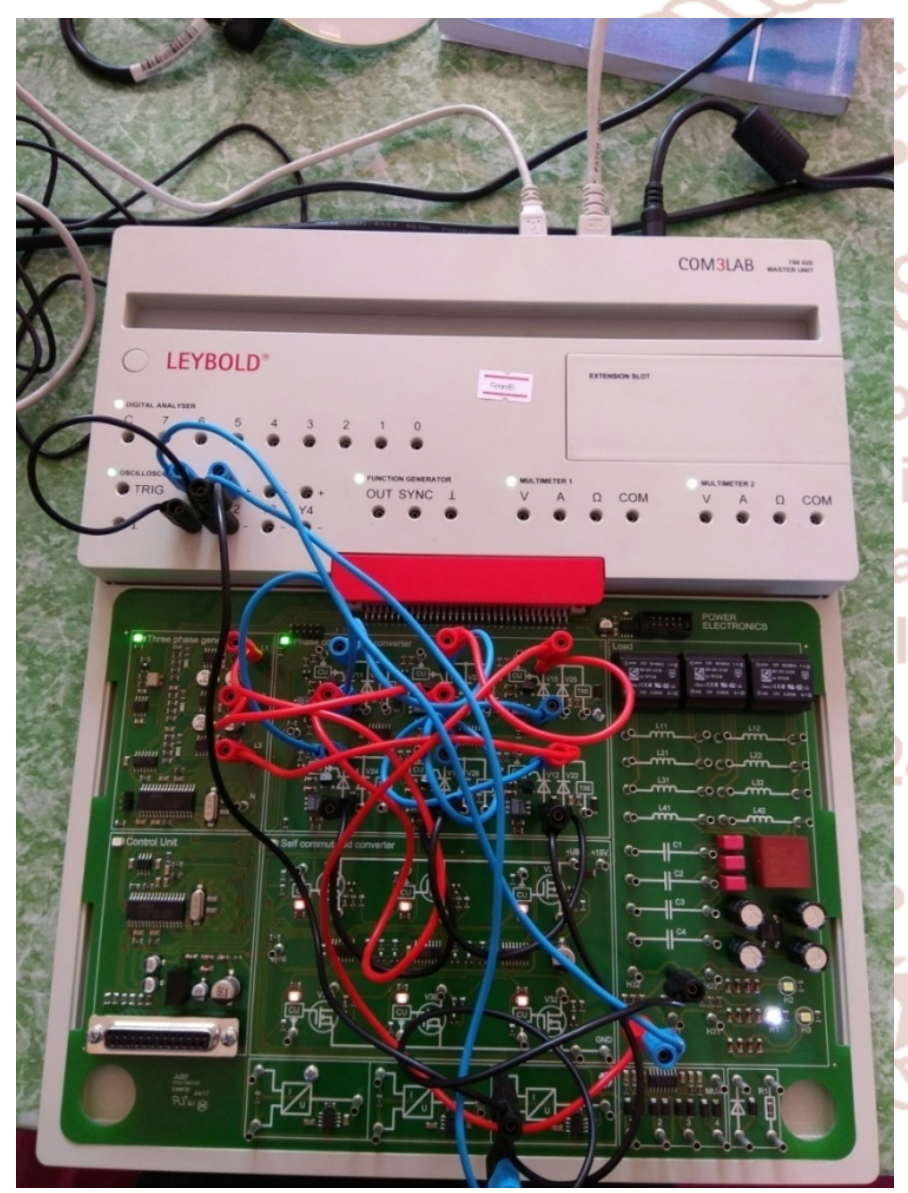

Figure-4.4 Connection diagram of single phase fullcontrolled full-wave rectifieron COM3LAB Experiment board

\section{Three Phase Uncontrolled Bridge Rectifier}

For an uncontrolled three-phase bridge rectifier, six diodes are used, and circuit again has a pulse numbers of six. For this reason, it is also commonly referred to as a six pulse bridge. The B6 circuit can be seen simplified as a series connection of two M3 threepulse center circuit. The three -phase bridge rectifier in symmetrical operation is thus decoupled from the neutral conductor or the earth of the main as voltage. The operation of a 3-phase uncontrolled bridge rectifier circuit is described. A three-phase uncontrolled bridge rectifier can be constructed using six diodes, the three-phase bridge rectifier circuit has three-legs, each phase connected to one of the three phase voltages. Alternatively, it can be seen that the bridge circuit has two halves, the positive half consisting of the diodes $\mathrm{D}_{1}, \mathrm{D}_{2}$ and $\mathrm{D}_{3}$ and the negative half consisting of the diodes $\mathrm{D}_{4}, \mathrm{D}_{5}$ and $\mathrm{D}_{6}$. At any time when there is current flow, one diode from each half conducts. If the phase sequence of the source be $\mathrm{R}, \mathrm{Y}$ and $\mathrm{B}$, the diodes are conducting in the sequence $\mathrm{D}_{1}, \mathrm{D}_{2}, \mathrm{D}_{3}, \mathrm{D}_{4}, \mathrm{D}_{5}, \mathrm{D}_{6}$ and so on.

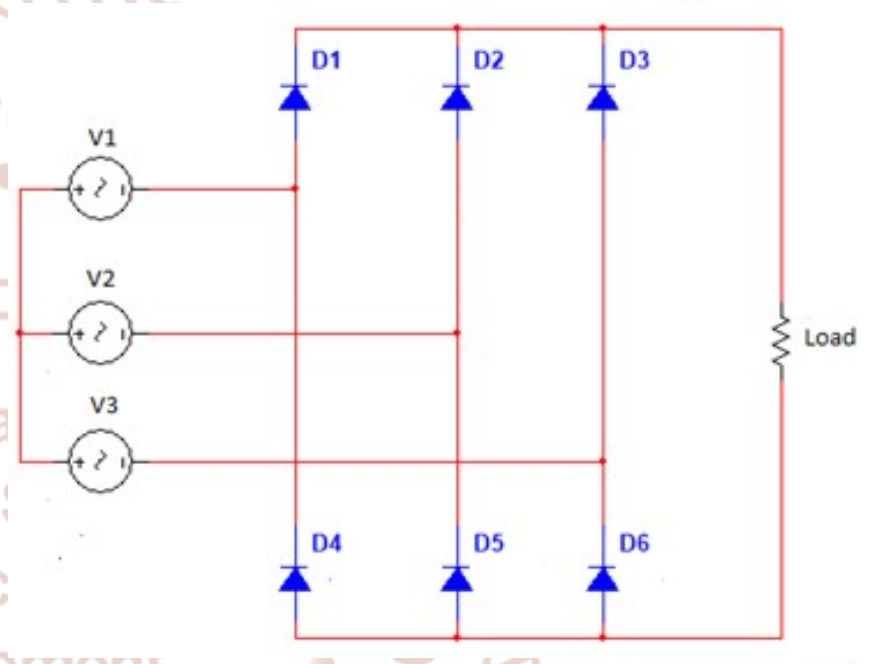

Figure-5.1Three phase uncontrolled bridgerectifier

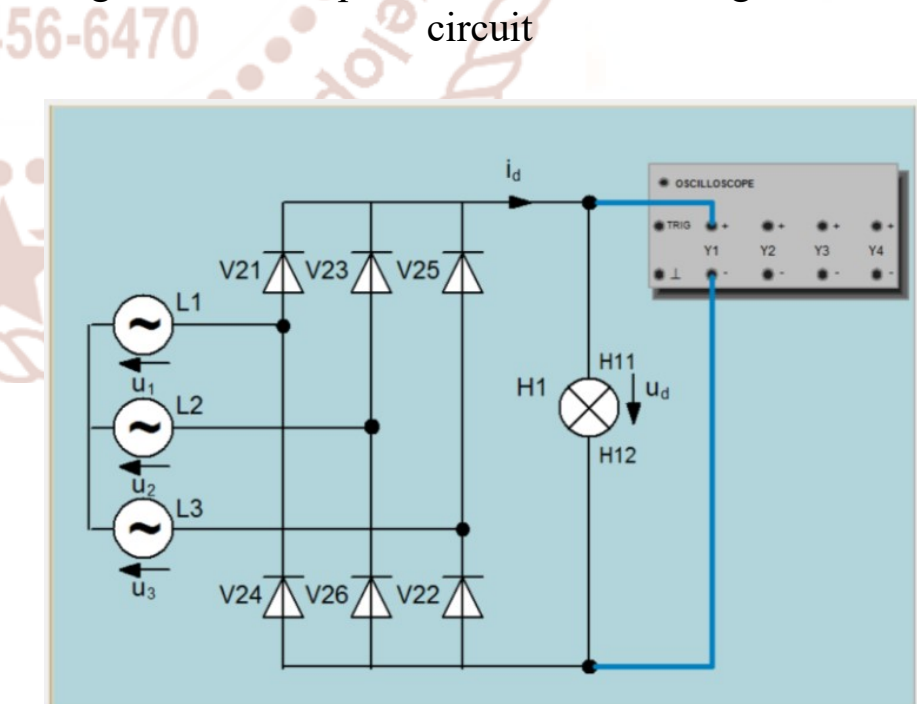

Figure-5.2Three phase uncontrolled bridgerectifier (Simulation model) 


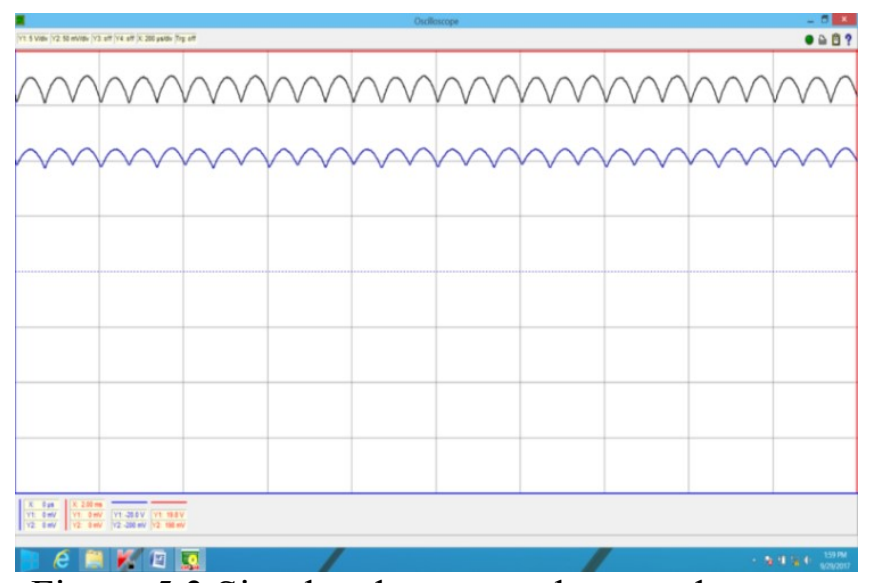

Figure-5.3 Simulated output voltage and current waveforms

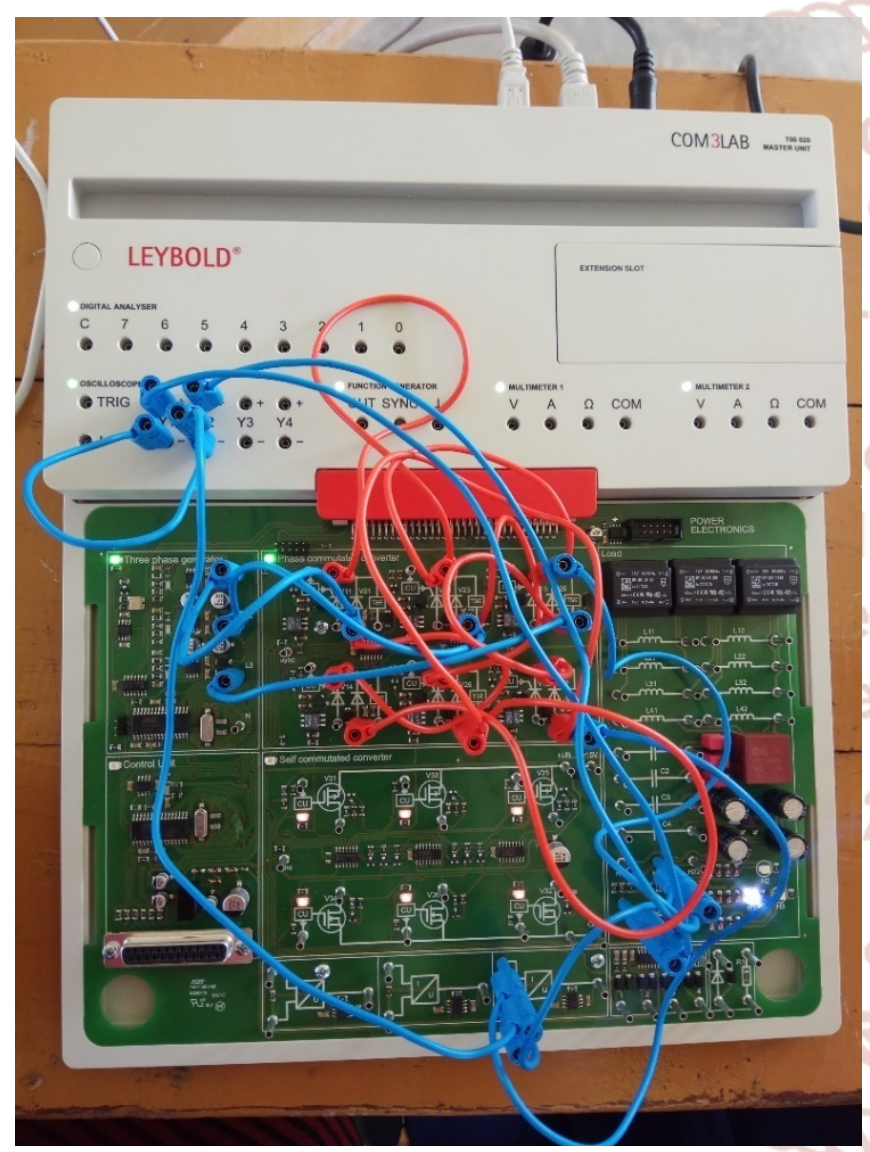

Figure-5.4 Connection diagram of three phase uncontrolled bridgerectifier on COM3LAB Experiment board

\section{Advantages and Limitations}

Advantages of using software in teaching power electronics include:

1. It provides better visual operations of power electronics converters.

2. Use of interactive learning software in classroom save the time of the faculty.

3. It can provide both theoretical and practical knowledge transfer from a single source.
4. Students can use this software for doing their project work.

The two main limitations with this software approach to identify the truth results are necessary of:

1. Technical know-how in COM3LAB teaching unit.

2. Depth knowledge of power electronics subject.

\section{Conclusion}

This paper provides the case study of visual operations of power electronics converters. As power electronics is one of the most important subjects for undergraduate electrical students, simulation used for education requires more features. This approach is time saving and holds the potential in providing better learning support with user-friendly interface, simulation speed and capability of simulating any type of power converter circuits. Students can implement and simulate the power electronics circuits with various load and conditions.

\section{Acknowledgment}

Special Thanks are due to all my teachers in Electronics Engineering Department (YTU), who provided creative guidance at all stages. The author would like to thank to all her colleges in for their invaluable supports.

\section{REFERENCES}

1. Biswanath Paul, "Industrial Electronics and Control Including Programmable Logic Controller, Third Edition", Published by Asoke K. All rights reserved.ISBN-978-81-203-4990-2.

2. Mohan, Undeland and Robbins, "Power Electronics: Converters, Applications, and Design", Wiley, 2003. ISBN-978-0-471-22693-2.

3. Introduction to Modern Power Electronics, https://www.azuretech.com

4. COMB3LAB Multimedia Learning System, http://www.researchgate.net

5. Prepared by- Dr. Mahmoud Kassas, "Power Electronics (EE460), Lab Manual-2006", http://www.kfupm.edu.sa

6. Mehar, H. and Nebhnani, N., " Software based Approach for Classroom Teaching of Electrical Engineering Courses: A Case Study". Journal of Technical Education and Training (JTET) /67. Vol. 7, N0.1,June 2015, ISSN 2229-8932. 